\title{
Men increase time spent on a charitable task when in the presence of women and other men: Evidence of competitive altruism in online mating scenarios
}

\author{
Shannon Farmer ${ }^{1}$ - Daniel Farrelly ${ }^{1}$ iD
}

Accepted: 29 July 2021

(C) The Author(s) 2021

\begin{abstract}
Previous research shows that competition can increase altruistic behaviour, however, the majority of such research focuses on financial costs and so our understanding is currently limited. Subsequently, the present study explored how competitive altruism can affect prosocial behaviour where time spent is the currency, using a real world charity. A sample of 67 men and 71 women completed the online altruistic task. As hypothesised, significant differences in giving behaviour due to competition were present in men but not women, suggesting that men use time spent here as a signal in mate choice scenarios. These findings therefore expand upon previous research on financial altruism, using artificial and/or hypothetical scenarios, by demonstrating that competitive altruism can be applied to real-world scenarios, where prosocial behaviours are of benefit. It also builds on previous research showing that men can compete with other men to display their altruistic nature to potential mates.
\end{abstract}

Keywords Prosociality $\cdot$ Competitive altruism $\cdot$ Charitable behaviour · Online

Altruistic behaviour, defined here as a behaviour that incurs a cost to the actor yet benefits another individual ${ }^{1}$ (Trivers, 1971), was recognised by Darwin (1871) as being problematic to his theory of evolution by natural selection. This is because it will reduce the fitness of the actor (by being costly), yet it is observed in both humans and animal species (e.g. Seyfarth \& Cheney, 1984; Wilkinson, 1984) which shows it is a common occurrence in nature, meaning it must have an adaptive benefit. In response to this, evolutionary theorists since Darwin have sought to explain how altruistic behaviour could be adaptive in terms of helping relatives (Hamilton, 1964) and reciprocity (Trivers, 1971). Attention has since turned to explaining the indirect benefits of altruistic behaviours (Alexander, 1987), where an individual's reputation for being altruistic leads to them in turn receiving more help from others

\footnotetext{
${ }^{1}$ The terms 'altruism' and 'altruistic behaviour' have different implications in different fields, although this definition will be used here. Please see Rodrigues and Hewig (2021) for a more in-depth and contemporary review of the debate on defining 'altruism'.
}

Daniel Farrelly

d.farrelly@worc.ac.uk

1 School of Psychology, University of Worcester, St John's Campus, Henwick Grove, Worcester WR2 6AJ, UK
(Nowak \& Sigmund, 1998; Wedekind \& Milinski, 2000). Such theories are thus better able to explain how altruistic behaviours can be adaptive in many different situations and scenarios, and not just between kin or within dyadic reciprocal relationships.

One such theory that suggests reputation is important is the competitive altruism hypothesis, which argues individuals compete with others to be seen as generous (Roberts, 1998). According to Roberts (1998), competitive altruism is a twostage process, whereby individuals compete with one another to be the most cooperative within a group in the first 'assessment' stage. This is because individuals can then join cooperative dyads in the second 'partnered' stage, where they can actively choose their partner. This results in assortative matching whereby the most cooperative individuals will choose each other, and form successful cooperative relationships where both benefit. However those that were less cooperative in the assessment stage will be less appealing partners so subsequently form less successful partnerships. Therefore this theory shows how competing to display one's altruistic behaviour in the presence of others can be adaptive. Experimental evidence of competitive altruism in humans has been shown in experimental games, where contributions were made public (Andreoni \& Petrie, 2004; Barclay \& Willer, 2006; Böhm \& Regner, 2013; Hardy \& van Vugt, 
2006) and also when partner choice for later paired cooperative games was available (Barclay, 2004; Sylwester \& Roberts, 2010).

It is not, however, only for future cooperative alliances that competitive altruism can be adaptive. Roberts (1998) also stresses that individuals could compete to display their altruistic behaviour to potential romantic partners, and be actively chosen by higher quality partners if they do so. This is based on altruistic behaviours being important in mate choice, and there is very strong evidence that this is indeed the case for humans (see Bhogal, Farrelly, \& Galbraith, 2019b for a recent review of the literature). Research here has often focused on female mate choice, which typically reflects that due to the asymmetry in parental investment between the sexes that leads to females investing more in offspring (Trivers, 1972), females are more 'choosy', as Darwin (1871) himself noted. As a result there is evidence that women find altruistic behaviours as being desirable in potential mates (e.g. Farrelly et al., 2016) and men display altruistic behaviour in the presence of potential mates (e.g. Tognetti et al., 2012).

Subsequently, research has shown that men will compete with one another to be the most altruistic in the presence of potential mates. In a laboratory-based experiment Tognetti et al. (2016) found that single men contributed more money to a public fund when they knew they were in a group composed of other men and at least one women. They also found no such effect of sex composition on the contributions of men in relationships or women, which leads the authors to suggest that single men are triggered to compete to be the most altruistic man in the group, as a means of signalling their quality in a mate choice context (Tognetti et al., 2016). Furthermore, Raihani and Smith (2015) directly tested the role of competitive altruism in mate choice scenarios by using online giving websites, and found that when donating to an attractive woman, men responded competitively (i.e. donated more) in response to previous donations from other men, yet female donors did not respond in a similar manner.

The above findings of Raihani and Smith (2015) demonstrate competitive helping displays by men in scenarios where real world altruistic behaviours are present (in this case, online charitable donations), and therefore adds to an existing body of literature that shows how social influences can lead to increased actual donations to charities (e.g. Powell et al., 2012; Reyniers \& Bhalla, 2013; Smith et al., 2015). However, the consistent use of financial costs as the default currency in this research is a limitation as it is not the only method through which it can occur, and so this focus may ignore alternative costs seen in everyday life, such as time spent (Farrelly et al., 2015; Farrelly \& Bennett, 2018; Lange \& Dewitte, 2021). The importance of exploring costs such as time, is that it is high in ecological validity and can have universal and equivalent understanding across populations (Bhogal, Bartlett, \& Farrelly, 2019a; Farrelly et al., 2015). Furthermore, the availability of financial resources varies greatly across populations and recent findings suggest that resource availability moderates the effect of environmental cues on monetary donations ( $\mathrm{Zhu}$ et al., 2019), making it an inappropriate measure of altruistic behaviour in such populations.

Therefore the current study will examine the potential role of competitive altruism in influencing people's real world charitable donations in different mate choice scenarios. As such it will build on the findings of Tognetti et al. (2016) and Raihani and Smith (2015) by exploring how the presence of potential competitors (i.e. members of the same sex) affect competitive helping behaviours in potential mate choice scenarios (i.e. when such behaviours are observed by members of the opposite sex), and in terms of the latter study will also examine this in an online charity environment. However unlike Tognetti et al. (2016) and Raihani and Smith (2015) this study will use time spent rather than money as the currency, more specifically the real-world charity Freerice website (www.freerice.com) which has been used previously in research (Farrelly \& Bennett, 2018). There it was found that participants induced with empathy spent more time answering general knowledge questions on the Freerice website, which translated to more donations of rice to the World Food Programme.

In this study, participants will be allocated to groups with leader boards displayed showing the performance in the game (i.e. amount of rice gained) of other group members, as well as details of the individual fundraiser who created the group. The displayed usernames of each group member and fundraiser were experimentally manipulated to signal each individuals' gender, so that different conditions created high or low levels of competition for the participants. As a result, the current study will test the following two hypotheses; men in the high competition condition (i.e. more donors of the same sex with fundraisers of the opposite sex) will spend significantly more time on the task than men in the low competition condition (i.e. when gender of fundraisers and donors are not known) whereas there will be no such effect of competition condition on the time spent on the task for women (hypothesis 1), and men will spend significantly more time on the task than women in the high competition condition, whereas there will be no difference in the time spent on the task between men and women in the low competition condition (hypothesis 2).

\section{Methods}

\section{Participants}

One hundred and thirty-eight participants (67 males; $71 \mathrm{fe}-$ males, $M=21.60, S D=4.00$ ) completed this study. The majority of participants were undergraduate students from a UK university, recruited via opportunity and volunteer sampling 
using SONA, a psychology research participation scheme, social media advertisement (i.e. Facebook) and the Survey Circle website. No other demographic details from participants were recorded. This study was approved by the university ethics committee.

\section{Materials}

Online Altruistic Task Freerice (https://freerice.com/about) is a website supporting the United Nations World Food Programme. Individuals can answer as many multiple-choice questions as they like, from a range of topics. For each question answered correctly, ten grains of rice are donated to the programme. As participants answered questions correctly, the number of rice grains that they had donated appeared on the screen, with a bowl of rice providing a visual representation. English vocabulary questions were used, which involved participants having to identify the correct definition of a word from a choice of four (e.g. partner means: thanks, penny, associate, kettle).

Leader Board Participants were presented with a leader board which contained a list of the current top ten contributors (in terms of amount of rice collected) by their usernames. The contribution of previous donors (i.e. total amount of rice donated) was not displayed on any of the above leader boards, as previous research found current donors use previous donations as an aim, therefore, this will gain a true representation of participants level of altruistic behaviour (Smith et al., 2015). Furthermore, at the top of the leader board were either the names of the individuals who had created the group or no such details (see below for rationale). There were three different versions of the leader board to create the different conditions of competition levels for male and female participants:

(1) High Competition Leader board (male participants). A leader board created by a group of women, displaying the usernames of previous male donors only.

(2) High Competition Leader board (female participants). A leader board created by a group of men, displaying the usernames of previous female donors only.

(3) Low Competition Leader board (male and female participants). A leader board displaying gender neutral usernames from previous donors only. Both men and women within the low competition condition viewed this leader board.

Examples of the study materials are publicly available (https://osf.io/rfvy7/?view_only=0a20e43d 883942 c7b677733fd5cce092).

\section{Procedure}

Upon beginning the study, participants read the information sheet and provided informed consent and demographic details (preferred gender, age). They were then randomly assigned to the high or low competition condition. Participants were then informed about Freerice as a charity, viewed the leader board and were informed they could play the game for as long as they wanted to. As leader boards were hypothetical, to minimise deception, they were described as representing potential groups on the Freerice website, which participants may join depending on their contribution and no additional details alongside usernames were added. A link took them to the Freerice website, where participants played the game for as long as they wished and then they returned to the survey page where they were required to enter their final score. Finally, a debrief containing more details of the study and thanks for participation was displayed on the last page.

\section{Design}

A $2 \times 2$ ANOVA with competition level (high or low) and gender (male or female) as between-subjects' independent variables was conducted, with altruistic task score (amount of rice collected) as the dependent variable. The study data is publicly available (https:// osf.io/rfvy7/?view_only=0a20e43d883942c7b677733fd5cce092).

\section{Results}

Hypothesis 1 Men in the High Competition Condition Will Spend Significantly More Time on the Task than Men in the Low Competition Condition, whereas there Will Be no Such Effect for Women

There was a statistically significant interaction between competition level and gender, on the task score, $F(1,134)=11.23$, $p=.001, \eta^{2}=.04$, and subsequent Bonferroni pairwise comparisons revealed that whereas men spent significantly more time on the task in the high $(M=781.18, S D=242.93)$ than the low competition ( $M=437.27, S D=236.94)$ condition, $t=6.78, p<.001$, there was no such difference between the high $(M=310.54$, $S D=197.15)$ and the low competition $(M=203.82, S D=$ 138.78) condition for women, $t=2.16, p=.19)$, See Fig. 1 below.

Hypothesis 2 Men Will Spend Significantly More Time on the Task than Women in the High Competition Condition, whereas there Will Be no Difference between Men and Women in the Low Competition Condition

Additional Bonferroni pairwise comparisons revealed that men spent significantly more time on the task than women did in the high competition condition, $t=9.54, p<.001$, and this was also the case in the low competition condition, $t=4.6$, $p<.001$, see Fig. 1 below. 
Fig. 1 Graph showing mean altruistic task score (and 95\% confidence intervals) by men and women when in high competition and low competition

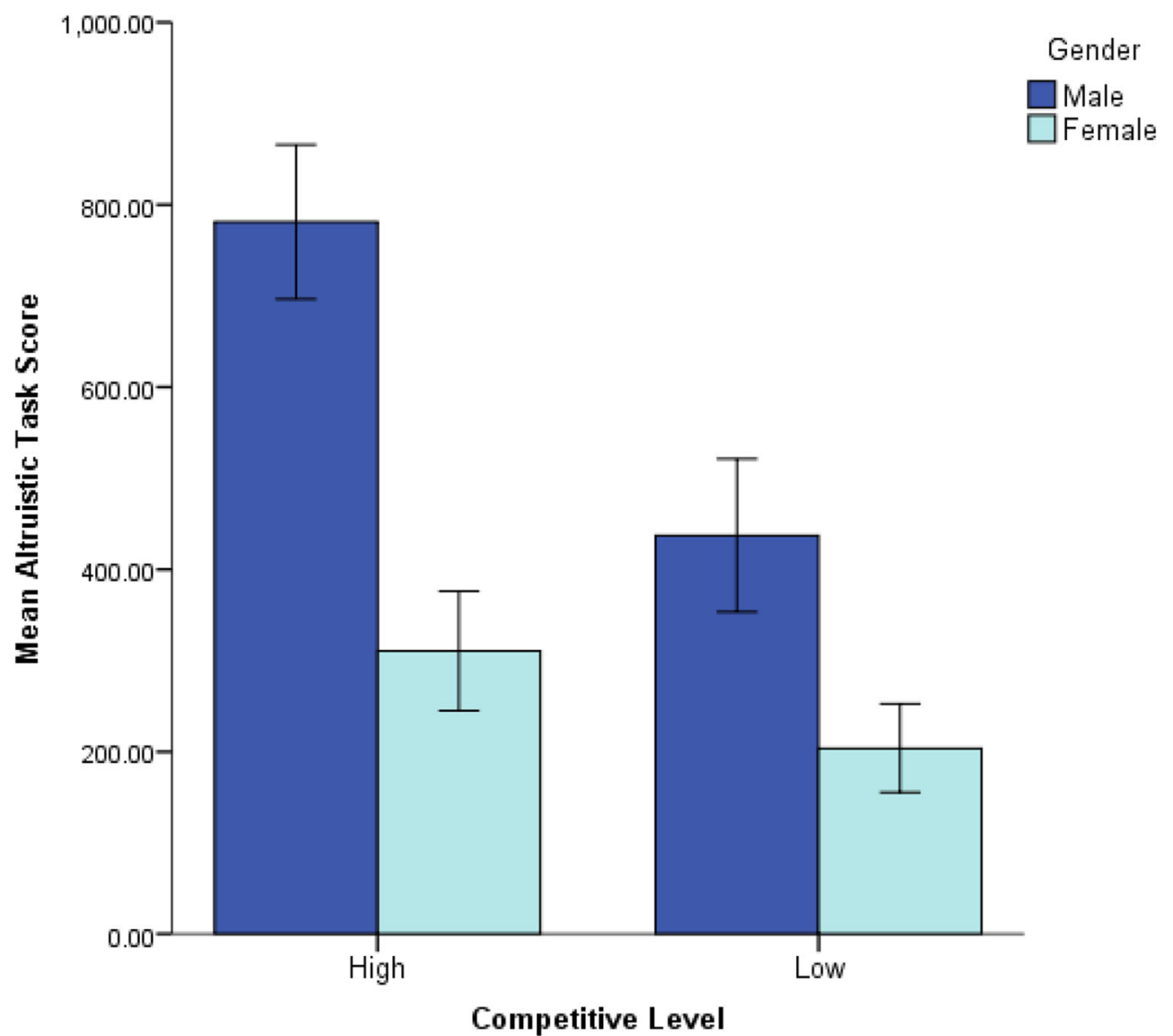

\section{Discussion}

Overall the results of the study provide support for the hypotheses. Firstly, men spent more time on the task in the high than the low competition condition, whereas there was no such difference for women's giving behaviour between conditions (hypothesis 1), and secondly men spent more time than women on the task in the high competition condition (hypothesis 2). However contrary to what was hypothesised there was a gender difference in time spent in the low competition condition, with men again spending more time on the task than women. A possible explanation for this unexpected finding is that there was still an element of competition in this condition, as although the gender neutral usernames were used, participants were still informed that scores would be made public. Previous research has shown that when behaviour is made public that competition to display altruistic behaviours increases (Andreoni \& Petrie, 2004; Barclay \& Willer, 2006; Böhm \& Regner, 2013; Hardy \& van Vugt, 2006) and in such cases men are more competitive even when no details of other group members are present (Böhm \& Regner, 2013). This suggests a similar effect may have occurred here in the low competition condition, when the mere presence of a publicly displayed signal of giving behaviour on a hypothetical leader board was enough to trigger mating motivations among male participants to compete more.

Overall these findings offer further support for the role that competitive altruism can have in shaping human giving behaviour (Andreoni \& Petrie, 2004; Barclay \& Willer, 2006; Böhm \& Regner, 2013; Hardy \& van Vugt, 2006) and also more specifically that men will compete to display their altruistic behaviour more in the presence of other men and when observed by women (Raihani \& Smith, 2015; Tognetti et al., 2016). However this finding is the first to show competitive altruism can lead to an increase in charitable behaviour when time is the currency rather than money. As such it adds to previous research that shows that time spent can be a valid measure of altruistic behaviour in response to the empathyaltruism hypotheses (Farrelly \& Bennett, 2018) and as a measure of pro-environmental behaviours (Lange \& Dewitte, 2021).

The value of such novel findings as in this study in relation to non-financial forms of altruistic behaviour are three-fold. Firstly, it provides evidence that the motivations that underlie competitive altruism can translate to different forms of costly behaviours and are not just idiosyncratic to financial donations. Related to this secondly, these findings show that time spent and other possible forms of non-financial displays of 
altruistic behaviour can be reliably used in future research to create a broader understanding of how social influences can affect altruistic behaviour. This therefore also allows more ecologically valid measures to be used in different environmental contexts where they may be more appropriate than financial costs, for example in populations where factors such as socioeconomic status vary greatly between participants, meaning the relative 'costs' of financial decisions by participants will also vary greatly, which can confound the results (Zhu et al., 2019). Thirdly and finally it shows that real world charities such as the Freerice programme that rely on nonfinancial behaviour are similarly affected by the same social influences that also affect empirical tests of altruistic behaviour that use financial costs. This means that these findings and others such as Farrelly and Bennett (2018) and Lange and Dewitte (2021) can be applied to influence and increase actual global contributions to online charities such as Freerice and similar others that may follow.

Despite such findings, certain limitations of the present study should be recognised, mainly relating to the validity of the study design. Firstly, the stimuli used to induce competition here were novel and hypothetical and therefore may not have fully induced competition in participants. However, previous research suggests people do attend to stimuli such as leader boards (Raihani \& Smith, 2015; Smith et al., 2015), and as participants responded in the ways hypothesised, it is expected that they did pay attention to these stimuli as intended. Nonetheless, future research may use methods such as completing the task in a lab with a researcher and/or other participants present in groups (with varying gender composition) as opposed to online, to emphasise more explicitly the public element of the task to induce competition (Bateson et al., 2006; Nettle et al., 2013; Powell et al., 2012).

In addition, as this study was conducted online, participants were required to self-report their score. Consequently, the results may be subject to social desirability bias, as participants may have reported a more favourable task score, i.e. a higher score than what they had actually gained. Therefore future investigations using this method can look to incorporate measures of social desirability, and also individual differences measures of altruistic behaviour (and more specifically in mating scenarios) as a means of assessing the construct validity in more depth. However, as discussed above, participants were not shown previous donations, so they did not know the normative score, and so had no information available on which to base their score, so it is anticipated that self reporting scores had a minimal effect on the results. Additionally, participants responded in line with the hypotheses, and rates of giving in the task were not incomparable to those found in Farrelly and Bennett (2018) where scores were recorded by the experimenter in person, suggesting it is unlikely they were dishonest and suggests a suitable degree of validity.
In spite of the discussed limitations, this study provides strong support that competitive altruism in mating scenarios can affect people's displays of non-financial acts of altruistic behaviour. Additionally, it has important implications, such as that altruistic behaviour can be fostered in society by encouraging individuals to publicly display their generosity, which can be done by individuals' behaviour as well as their financial contributions. Future research can also explore whether this finding is cross-cultural to get a more universal perspective on how competition can influence all forms of altruistic behaviour. This can provide insights to charities aiming to increase all forms of interactions from the public, suggesting that adding competition in some way to their appeals will increase giving, particularly from male donors.

\section{Declarations}

Conflict of interest On behalf of all authors, the corresponding author states that there is no conflict of interest.

Open Access This article is licensed under a Creative Commons Attribution 4.0 International License, which permits use, sharing, adaptation, distribution and reproduction in any medium or format, as long as you give appropriate credit to the original author(s) and the source, provide a link to the Creative Commons licence, and indicate if changes were made. The images or other third party material in this article are included in the article's Creative Commons licence, unless indicated otherwise in a credit line to the material. If material is not included in the article's Creative Commons licence and your intended use is not permitted by statutory regulation or exceeds the permitted use, you will need to obtain permission directly from the copyright holder. To view a copy of this licence, visit http://creativecommons.org/licenses/by/4.0/.

\section{References}

Alexander, R. D. (1987). The Biology of Moral Systems. Aldine de Gruyter

Andreoni, J., \& Petrie, R. (2004). Public goods experiments without confidentiality: A glimpse into fund-raising. Journal of Public Economics, 88, 1605-1623.

Barclay, P. (2004). Trustworthiness and competitive altruism can also solve the "tragedy of the commons". Evolution and Human Behaviour, 25, 209-220.

Barclay, P., \& Willer, R. (2006). Partner choice creates competitive altruism in humans. Proceedings of the Royal Society B: Biological Sciences, 274, 749-753.

Bateson, M., Nettle, D., \& Roberts, G. (2006). Cues of being watched enhance cooperation in a real-world setting. Biology Letters, 2, 412 414.

Bhogal, M. S., Bartlett, J. E., \& Farrelly, D. (2019a). The influence of mate choice motivation on non-financial altruism. Current Psychology, 38, 959-964.

Bhogal, M. S., Farrelly, D., \& Galbraith, N. (2019b). The role of prosocial behaviors in mate choice: A critical review of the literature. Current Psychology, 38, 1062-1075. 
Böhm, R., \& Regner, T. (2013). Charitable giving among females and males: An empirical test of the competitive altruism hypothesis. Journal of Bioeconomics, 15, 251-267.

Darwin, C. (1871). The descent of man, and selection in relation to sex. John Murray.

Farrelly, D., \& Bennett, M. (2018). Empathy leads to increased online charitable behaviour when time is the currency. Journal of Community \& Applied Social Psychology, 28, 42-46.

Farrelly, D., Moan, E., White, K., \& Young, S. (2015). Evidence of an alternative currency for altruism in laboratory-based experiments. Europe's Journal of Psychology, 11, 100-111.

Farrelly, D., Clemson, P., \& Guthrie, M. (2016). Are women's mate preferences for altruism also influenced by physical attractiveness? Evolutionary Psychology, 14, 1-6.

Hamilton, W. D. (1964). The genetic evolution of social behaviour. I \& II. Journal of Theoretical Biology, 7, 1-52.

Hardy, C. L., \& van Vugt, M. (2006). Nice guys finish first: The competitive altruism hypothesis. Personality and Social Psychology Bulletin, 32, 1402-1413.

Lange, F., \& Dewitte, S. (2021). The work for environmental protection Task: A consequential web-based procedure for studying pro-environmental behavior. Behavior Research Methods. https://doi.org/10. 3758/s13428-021-01617-2

Nettle, D., Harper, Z., Kidson, A., Stone, R., Penton-Voak, I. S., \& Bateson, M. (2013). The watching eyes effect in the dictator game: it's not how much you give, it's being seen to give something. Evolution and Human Behaviour, 34, 35-40.

Nowak, M. A., \& Sigmund, K. (1998). Evolution of indirect reciprocity by image scoring. Nature, 393, 573-577.

Powell, K. L., Roberts, G., \& Nettle, D. (2012). Eye images increase charitable donations: Evidence from an opportunistic field experiment in a supermarket. Ethology, 118, 1096-1101.

Raihani, N. J., \& Smith, S. (2015). Competitive helping in online giving. Current Biology, 25, 1183-1186.

Reyniers, D., \& Bhalla, R. (2013). Reluctant altruism and peer pressure in charitable giving. Judgement and Decision Making, 8, 7-15.
Roberts, G. (1998). Competitive altruism: From reciprocity to the handicap principle. Proceedings of the Royal Society B: Biological Sciences, 265, 427-431.

Rodrigues, J., \& Hewig, J. (2021). Let's call it altruism! A psychological perspective and hierarchical framework of altruism and prosocial behavior [preprint]. PsyArXiv. https://doi.org/10.31234/osf.io/ pj7eu.

Seyfarth, R. M., \& Cheney, D. L. (1984). Grooming, alliances and reciprocal altruism in vervet monkeys. Nature, 308, 541-543.

Smith, S., Windmeijer, F., \& Wright, E. (2015). Peer effects in charitable giving: Evidence from the (running) field. Economic Journal, 125, 1503-1071.

Sylwester, K., \& Roberts, G. (2010). Co-operators benefit through reputation-based partner choice in economic games. Biology Letters, 6, 659-662.

Tognetti, A., Berticat, C., Raymond, M., \& Faurie, C. (2012). Sexual selection of human cooperative behaviour: An experimental study in rural Senegal. PLoS One, 7, e44403-e44403.

Tognetti, A., Dubois, D., Faurie, C., \& Willinger, M. (2016). Men increase contributions to a public good when under sexual competition. Scientific Reports, 5. https://doi.org/10.1038/srep11913

Trivers, R. (1971). The evolution of reciprocal altruism. Quarterly Review of Biology, 46, 35-57.

Trivers, R. L. (1972). Parental investment and sexual selection. In B. Campbell (Ed.), Sexual selection and the descent of man, 18711971 (pp. 136-179). Aldine.

Wedekind, C., \& Milinski, M. (2000). Cooperation through image scoring in humans. Science, $288,850-852$.

Wilkinson, G. S. (1984). Reciprocal food sharing in the vampire bat. Nature, 308, 181-184.

Zhu, N., Hawk, S. T., \& Chang, L. (2019). Unpredictable and competitive cues affect prosocial behaviours and judgments. Personality and Individual Differences, 138, 203-211.

Publisher's note Springer Nature remains neutral with regard to jurisdictional claims in published maps and institutional affiliations. 